International Research Conference on Civil, Architectural and Environmental Engineering

(IRCCAEE)

Istanbul (Turkey) May 17-18, 2017

\title{
Assessment of Sustainable Sanitation Systems: Urban Slums
}

\author{
Ali Hamza ${ }^{1}$, Menal Zaheer ${ }^{2}$, Bertuğ Akıntuğ ${ }^{1}$ \\ ${ }^{1}$ Sustainable Environment and Energy Systems, Middle East Technical University, Northern Cyprus Campus, \\ Kalkanl1, Güzelyurt, Mersin 10, Turkey (ali.hamza@ metu.edu.tr and bertug@ metu.edu.tr) \\ ${ }^{2}$ College of Earth and Environmental Sciences (CEES), University of Punjab, Lahore, \\ Pakistan (menal.zaheer@hotmail.com)
}

\begin{abstract}
Having an appropriate plan of sanitation systems is one of the critical issues in global urban slums nowadays. Poor sanitation systems in urban slums outcomes an enhanced vulnerability of severe diseases, low hygiene, and environmental risks within our environment. Greywater, human excreta, and solid waste are the main contributors increasing public health risks and amounts of pollution loads within the slum environment. Higher population growth, urge of urbanization and illegal status of urban slums makes it impossible to increase the level of performance of sanitation systems in urban slums. According to Sustainable Sanitation Alliance, design parameters for sanitation systems are set up to ensure sustainable environment. This paper reviews the categories of effluent, treatment technologies, and procedures of processes that are adopted in the urban slums. Based on these considerations, assessment of sustainable sanitation systems is done using sanitation chain concept in accordance to the pre-determined sustainability indicators and criteria which shows that this concept is potentially feasible and applicable in terms of sustainable sanitation in urban slums.
\end{abstract}

Keywords: Urban Slum, Sanitation Systems, Excreta, Sustainability, Sanitation Chain

\section{Introduction}

\subsection{Slum Sanitation}

"Sanitation" could be defined in terms of environment referring to the maintained hygiene conditions of living beings in the environment. The scope of sanitation includes human excreta disposal, household wastewater disposal, and solid waste management techniques [1]. Improvement of sanitation systems in urban slums is one of the most highlighted issues, as improper sanitation systems results in public health risks including contracting diseases such as cholera, worms, diarrhea, skin/eye irritations and others [2]. Although, according to United Nations Millennium Development Goals, the sanitation target is being formulated in making it possible to cover improved sanitation systems in slums areas; low investments have been seen providing a minimal coverage of sanitation such as improved toilets and pit latrines in many urbans slums around the world. However, comparing with the target formulated, there is still low quality of sanitation with high quantities of undisposed excreta waste and insufficient work is done in terms of treatment and sanitation of accumulated waste from the urban slums. Higher density of population is converting urbanization into urban slums in many parts of the world resulting in the issues of over-flowing pit latrines, disposal of excreta waste on the streets and open drains; regarded as common within the past few years $[2,3]$.

\subsection{Effects of Substandard Sanitation and Public Health Risk}

Sanitation standards have its main concerns in terms of urbanization and public health. The public health scenario in urban slums is adverse, as the vulnerability of environmental pollution is at its peak. The inadequate conditions of sanitation systems are thus, a threat to human lives living in urban slums. Apart from surface 
contamination, groundwater contamination is also witnessed; water in the wells are contaminated with excreta and wastewater which increase the risks of having "Escherichia Coli" virus within the water and make it exposed to harmful pathogens, micro pollutants, and unwanted nutrients. $[4,5]$.

\subsection{Sustainable Sanitation Systems}

Sustainable sanitation systems that include more aspects such as the system should be financially and economically feasible, socially agreed, and accepted, must be technologically innovative, efficiently appropriate and feasible, and protect the environment from the environmental risks [6]. According to Sustainable Sanitation Alliance, for the design of new sustainable sanitation systems, following aspects should be taken into consideration [7]:

- Health and Hygiene - The risk of human vulnerability of pathogens within the sanitation systems should be reduced.

- Environment - For a sanitation system, the accountability should be evaluated for the need of energy, water, and natural resources during the construction, operation, and maintenance of the system. Toxic waste and harmful emissions should also be monitored and mitigated with considerable implementation.

- Technology and Operation - The functionality of the systems should be technologically viable. The robustness and sensitivity of the systems must be evaluated.

- Economy - Willingness to pay for the sanitation system is important; including all costs such as construction, operations, and investments. Additional costs such as environmental pollution and toxic emission taxes should also be implemented and monitored.

- Socio - Cultural Aspects - The sanitation system should be convenient, with less gender issues and have more emphasis on human's life value.

Sanitation systems should include efficient ways for collecting waste, storage facilities, conveyance to treatment plants, and innovative treatment facilities of human waste with improved and safe reuse or disposal of waste products in terms of benefitting the environment [8]. Considering urban slums and sanitation systems, population density, landscape and topographic conditions, settlement patterns, water availability and quality, economic incomes and social issues are also addressing factors which cannot be ignored. Considering these problems, this paper reviews the existing sanitation systems implemented in the urban slums, along with the types of waste effluents characterization. Furthermore, the development of sustainable sanitation chain concept for the sanitation systems based on urban slum's topographic conditions such as provisions for waterless sanitation systems is discussed. Also, assessment of these proposed sanitation systems in accordance to the sustainability indicators and criteria mentioned in the latter parts of the paper is evaluated.

\section{Literature Review}

The main waste effluents in the urban slums causing environment pollution are human excreta, greywater, and solid wastes [9]. Waste effluents include high proportions of biological pathogens, micro-pollutants, nutrients, and other forms of organic waste. For providing technological efficient sanitation system in urban slums, understanding the characteristics of these waste effluent components is essential to overcome the major problems of sanitation in urban slums.

\subsection{Human Excreta}

Human excreta includes only urine and faeces causing major hygiene risk due to the existence of pathogens in faeces, nutrients in urine and presence of micro-pollutants. Generally, open pits and storm water drains are contaminated by human excreta, increasing the vulnerability towards public health within the slum environment. Although, pit latrines are designed to seep the liquid inside the soil, but the risk of groundwater contamination is another major environment concern in urban slums. Human excreta's major contaminants components include organic matter in the form of Chemical Oxygen Demand (COD), pathogens, Phosphorus (P), and Nitrogen (N) enriched nutrients in the forms of bacteria, viruses and parasites [2]. 


\subsection{Grey Water}

Grey water, defined as urban wastewater that includes water from showers, bathrooms, hand basins, laundry use, dishwashers, and kitchen sinks excluding effluents from toilets. Greywater approximately accounts for $65-$ $75 \%$ of the total domestic wastewater consumption. This range can be a good estimate of return variable of grey water produced in the urban slums. Grey water contaminants include suspended and dissolved solids, nutrients, pathogens, and also organic micro-pollutants with minor amounts of urine contamination. All grey water types show high levels of biodegradability as shown by their BOD5: COD ratio, which is close to 50\% [10]. Grey water quality mainly depends on the population responses, source location, and the level of sanitation systems. In the case of urban slums, uncontrolled amounts of grey water release require extensive amounts of treatment including the removal of COD loads, nutrients, and pathogens.

\subsection{Solid Waste}

Solid Waste management is considered to be the most crucial issues in terms of sanitation sustainability. The increased amounts of organic waste, mainly because of urbanization and population growth, have adverse impacts on environment extensively. Low levels of management of solid waste in urban slums (organic matter) could increase exponentially. Green House Gases (GHGs) emissions from solid waste pits and dumps. The uncollected waste aggravates the chances of leaching of nutrients and organic matter in the soil, contaminating the groundwater levels, choking of open drains, and progressing the vulnerability of floods in urban slums; thus disturbing the overall balance of ecosystem.

\section{Methodology}

\subsection{Sanitation Chain System Concept}

Sanitation systems include a lifecycle; a step wise provisions of using sanitation facilities achieving satisfactory improvement in public health and environment. The concept of these series of steps are normally called as sanitation chain system. Sanitation chain system includes a series of operations such as production, capture, collection and transport, treatment or disposal, and reuse [11].

Sanitation chain system concept follows a logical order in which individual processes are interlinked with each other. These processes can be categorized as [11]:

- Processes for disposal and collection of excreta from the user interface.

- Processes for collection and conveyance of waste (excreta).

- Processes for treatment and reuse of waste (excreta) or safe disposal.

Each process is taken individually, as the importance of each process is concerned with the sustainability of the sanitation system. Each process includes a variety of individual components based on the requirements of different types of technologies. The sanitation chain system concept involves complex considerations with respect to all the sanitation technologies for each waste effluent [11].

In this sanitation chain concept system, only excreta will be discussed. Sanitation chain concept can be applied on any sanitation system irrespective of its arrangement i.e. Centralized, semi centralized, and decentralized arrangements. Because of having improper and informal settlement patterns, it is difficult to implement centralized arrangement for urban slums [3, 12].

Therefore, semi centralized or decentralized arrangements are preferred for urban slums. Using the sanitation chain system concept, the sanitation facilities can be made sustainable for the slum dwellers, improving the health and environmental conditions of urban slums.

\section{Assessment of Sanitation Systems}

\subsection{Pit Latrine Systems}

Pit Latrine systems are the most common type of excreta disposal system in urban slums. Pit sanitation includes different types of pits; from traditional single pit systems to ventilated improved pits. Severe environmental issues such as high water table with increased amount of contaminants, ground water pollution 
because of excreta seepage from the unlined pit latrines, overflow of excreta during rainy seasons from the pit latrines, and filling rate of pit latrines are the major challenges in terms of safe sanitation. In urban slums, the accessibility for vehicles for emptying the pit latrines is quite low resulting in the unattended excreta, which causes high vulnerability of health for the slum dwellers $[2,3,12]$.

One of the many alternative and sustainable technologies proposed and implemented is the single pit system, which is based on the use of single pit for collecting and storage of excreta. This system doesn't require water for its functionality but the requirements of flush water and anal cleansing water will depend on the type of community and the water availability in a certain urban slum [9]. The user interface is connected to the single pit, for the collection and storage. The system is presented in Fig. 3 [12].

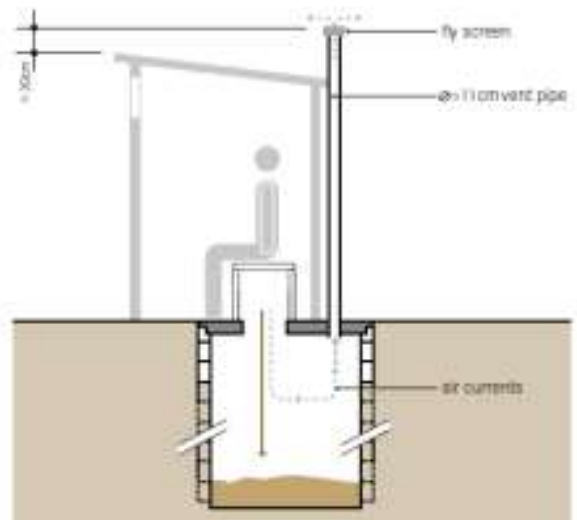

Fig. 1: Single Pit System [14].

Based on this single pit system, other similar systems were also established amongst which, waterless pit systems with urine diversions and without sludge production were introduced. For waterless pit systems with urine diversion, urine diverting dry toilets (UDDT) are used, for separation of urine and faeces. Fig. 2 shows the dehydration vaults (reduced pathogen concentration) used for the collection and storage of faeces [12].

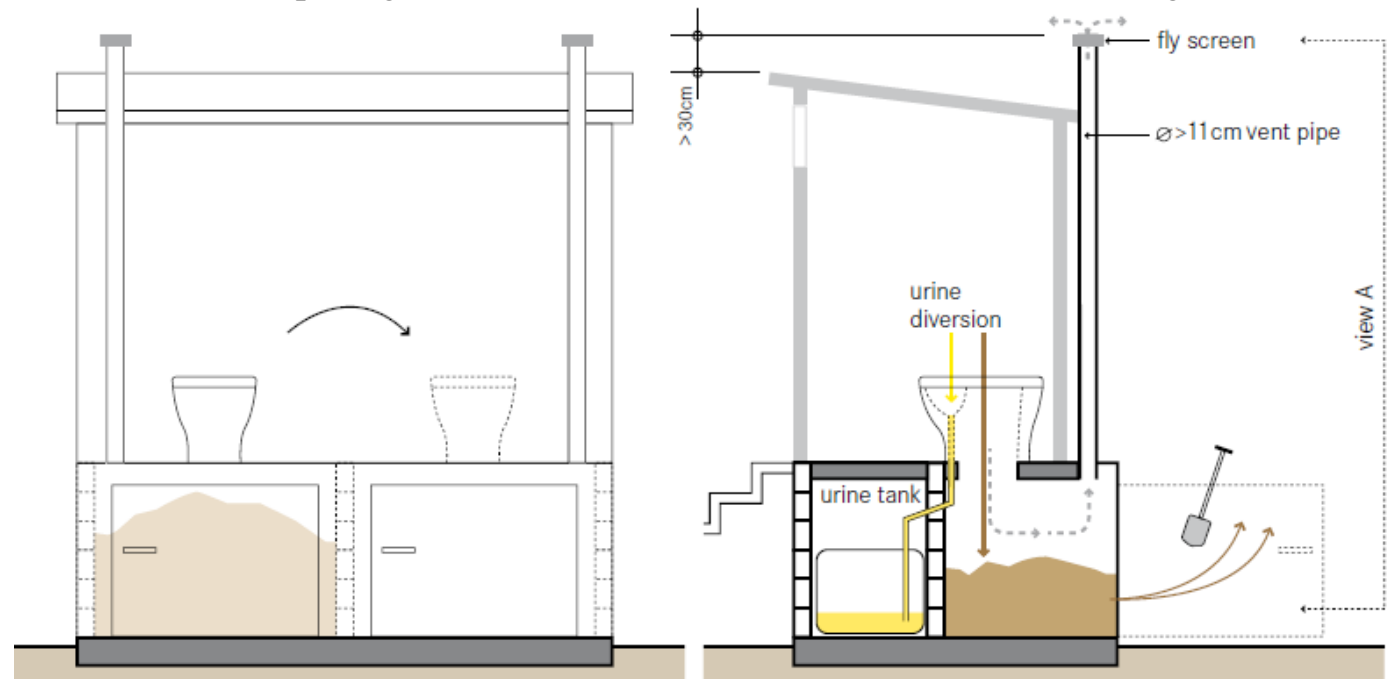

Fig. 2: Waterless System with Urine Diversion [14].

For implementation of these sanitation systems in urban slums, several factors are important to be taken into consideration. For single pit systems, it can only be implemented where there is enough space for digging new pits and provide feasible ways for emptying, treatment, and disposal of faecal sludge. Soil should also be appropriate enough for digging pits and for absorbing the leachate. This system might fail where there is more chances of heavy rainfalls and flooding conditions, which may cause the pits to overflow failing the system. 


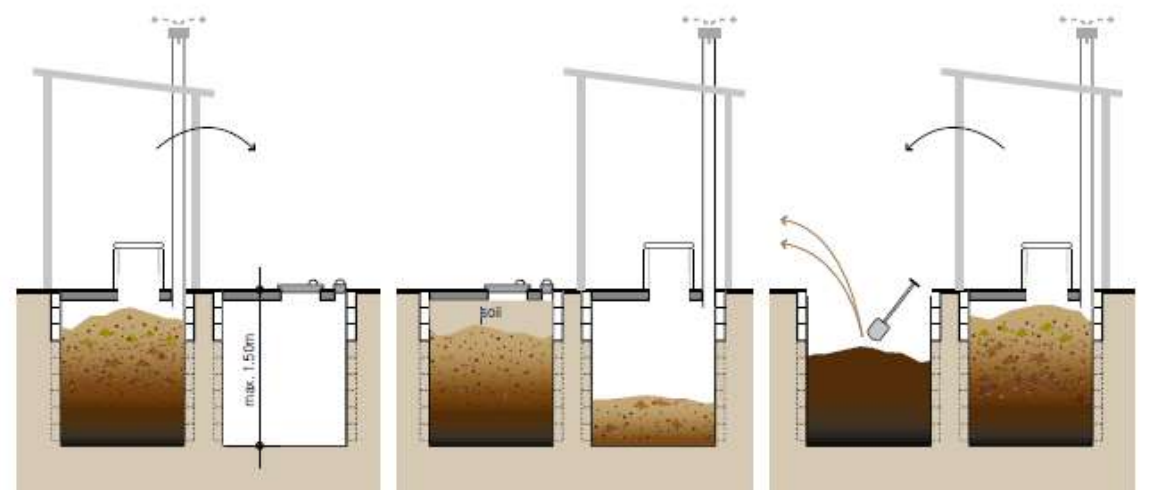

Fig. 3: Waterless Systems without Sludge Production [14].

This system is regarded as the least expensive system but requires maintenance for emptying the pit from time to time. Normally, the pit digging is preferred up to 5 meters and can be used for a long period of time without emptying for single pit system if proper maintenance is promised [12]. Otherwise, there will be a constant threat of groundwater contamination, if maintenance is not taken into consideration.

For waterless systems without sludge production, this can be the permanent system where space is limited and two pits can be used indefinitely. This system would be easy implemented in urban slums as the product needs manual removal. For agricultural purposes, the reuse of humus product as a soil conditioner is quite a sustainable by product of excreta. The success of this system depends on the proper operational maintenance and extended storage period. For improving the decomposition process, making the pit well aerated might be helpful. But too much moisture within the pit might fill up the air voids of sludge and won't allow oxygen to react with the microorganisms present, spoiling the decomposition process.

\subsection{Sustainability of Sanitation Systems}

Not all the sanitation systems options are compatible in every scenario. Sustainability aspects such as technology, socio-culture, hygiene, economical value, and institutional are important for evaluation of each sanitation system selected for a specific urban slum [7]. Using these sustainability aspects, each sanitation system can be evaluated and ranked between all other alternative sustainable sanitation systems discussed for implementing in urban slums [1-3].

Waterless pit system with urine diversion is ranked highest because of its properties of maintenance and remedial works with easily accessible materials for construction from the urban slums is much appreciated. Land use is minimum with no requirements of water. These attributes can increase the life of the system since it can be emptied for reuse. It is also suitable for flood risk areas, due to urine diversion; more odor control with limited amounts of mixing of waste streams. Although single pit system works on the same function as the urine diversion system; poor sanitation practices, unattended single pits leading towards groundwater contamination, and unimproved excreta disposal facilities from this particular sanitation practice reduced the sustainability aspect of single pit systems.

Waterless pit system without sludge production ranked third because of the complexity of the system. Although, easily accessible materials from the slums can be used for construction and the system needs no water for functionality. Still, usage of two pits from time to time, proper operation of the system, maintaining the control of extended storage period, and requirements of secondary treatments for the compost matter could be the major challenges for the system which needs to be taken under consideration for efficient use of this system.

\section{Conclusion}

Assessment of sustainable sanitation system for any urban slum can only be possible if affecting factors are considered based on the type of location, waste effluents, economical value, society social, and cultural values. Considering all these factors, a sanitation chain system concept is adopted to assess all the suitable sanitation systems that can be implemented considering "no water requirement" in urban slums. Single pit systems are the most common type of excreta disposal system, but it is difficult to maintain on sustainable requirements because the higher risks of polluted water and mitigation of ground water contamination is not feasible. 
Waterless systems with urine diversion is considered to be attractive and less costly technological solution that has provision of separating excreta that reduces health risks associated with the society of urban slums. Nutrient recycling and beneficial use in agricultural sector is also one of the outcomes of this system depending on the land availability and the use of urine as an effective by product. Waterless systems without sludge production can become more likely to be implemented in urban slums with semi-centralized or decentralized considerations and arrangement of sanitation to produce sludge as soil conditioner, only if the sludge is treated properly for safe disposal and reuse and highly expertise labor is required for maintaining the system processes.

These sanitation systems need to be tested and evaluated on a small scale level in various urban slums of world before implementing them on a large scale for any respective urban slum. Acceptance from users and identifying the requirements of sanitation system will be considered as the main inputs using sanitation chain system concept, for finding a sustainable sanitation option. All the steps in this concept are necessary, for choosing the system irrespective of geographic location of slum; this system might not be able to forecast the long term planned effects of the technologic innovation presented based on implementing new sanitation options, but permits formulating a choice among all the sustainable options by mixing technological, social and economic sustainability.

\section{References}

[1] Zakaria, F., Garcia, H.A., Hooijmans, C.M., Brdjanovic, D., 2015. "Decision support system for the provision of emergency sanitation". Sci. Total Environ. 512-513, 645-658. doi:10.1016/j.scitotenv.2015.01.051

https://doi.org/10.1016/j.scitotenv.2015.01.051

[2] Katukiza, A.Y., Ronteltap, M., Niwagaba, C.B., Foppen, J.W.A., Kansiime, F., Lens, P.N.L., 2012. Sustainable sanitation technology options for urban slums. Biotechnol. Adv. 30, 964-978. doi:10.1016/j.biotechadv.2012.02.007

https://doi.org/10.1016/j.biotechadv.2012.02.007

[3] Katukiza, A.Y., Ronteltap, M., Oleja, A., Niwagaba, C.B., Kansiime, F., Lens, P.N.L., 2010. Selection of sustainable sanitation technologies for urban slums - A case of Bwaise III in Kampala, Uganda. Sci. Total Environ. 409, 52-62. doi:10.1016/j.scitotenv.2010.09.032

https://doi.org/10.1016/j.scitotenv.2010.09.032

[4] Nakagawa, N., Hana, O.E., Otaki, M., Ishizaki, K., 2006. Application of microbial risk assessment on a residentiallyoperated Bio-toilet. J. Water Health 4, 479-486. doi:10.2166/wh.2006.028

[5] Nyenje, P.M., Foppen, J.W., Uhlenbrook, S., Kulabako, R., Muwanga, A., 2010. Eutrophication and nutrient release in urban areas of sub-Saharan Africa - A review. Sci. Total Environ. 408, 447-455. doi:10.1016/j.scitotenv.2009.10.020

Larsson, E., Nilsson, M., 2013. Towards sustainable sanitation in slum areas: A field study in Mumbai. Technical Report, Linköpings Universitet.

Avaialble: http://www.diva-portal.org/smash/get/diva2:640967/FULLTEXT01.pdf

https://doi.org/10.1016/j.scitotenv.2009.10.020

[6] Sustainable Sanitation Alliance, 2008. 4 - Sanitation Systems, Hygiene \& Health.

Available: http://www.susana.org/en/working-groups/sanitation-systems-hygiene-health

[7] Mara, D., Drangert, J.-O., Nguyen, V.A., Tonderski, A., Gulyas, H., Tonderski, K., 2007. Selection of sustainable sanitation arrangements. Water Policy 9, 305-318. doi:10.2166/wp.2007.009

https://doi.org/10.2166/wp.2007.009

[8] Kulabako, N.R., Nalubega, M., Thunvik, R., 2007. Study of the impact of land use and hydrogeological settings on the shallow groundwater quality in a peri-urban area of Kampala, Uganda. Sci. Total Environ. 381, 180-199. doi:10.1016/j.scitotenv.2007.03.035

https://doi.org/10.1016/j.scitotenv.2007.03.035

[9] Li, F., Wichmann, K., Otterpohl, R., 2009. Review of the technological approaches for grey water treatment and reuses. Sci. Total Environ. 407, 3439-3449. doi:10.1016/j.scitotenv.2009.02.004 https://doi.org/10.1016/j.scitotenv.2009.02.004

[10] van Dijk, 2012. Sanitation in Developing Countries: Innovative Solutions in a Value Chain Framework, InTech. Available: http://cdn.intechopen.com/pdfs-wm/33283.pdf. 
[11] Dzwairo, B., Hoko, Z., Love, D., Guzha, E., 2006. Assessment of the impacts of pit latrines on groundwater quality in rural areas: A case study from Marondera district, Zimbabwe. Phys. Chem. Earth Parts ABC, Water for Sustainable Socio-Economic Development, Good Health for All and Gender Equity 31, 779-788. doi:10.1016/j.pce.2006.08.031 https://doi.org/10.1016/j.pce.2006.08.031

[12] Tilley E., Ulrich, L., Lüthi, C., Reymond, P., and Zurbrügg, C., 2016. Compendium of Sanitation Systems and Technologies. $2^{\text {nd }}$ Revised Edition. Available: http://www.iwa-network.org/wp-content/uploads/2016/06/CompendiumSanitation-Systems-and-Technologies.pdf 